\title{
Experiencia con rituximab en miopatía inflamatoria idiopática refractaria
}

\author{
Experience with rituximab in refractory idiopathic inflammatory myopathy
}

\author{
Elmer R. García-Salazar ${ }^{1,2, a}$, Felipe Becerra ${ }^{2, b}$, José Chávez ${ }^{2, b}$ \\ ${ }^{1}$ Unidad Ambulatoria de Reumatologia (UNAR), Servicio de Reumatología, Hospital Nacional Edgardo Rebagliati Martins, EsSalud, Lima, Perú. \\ ${ }^{2}$ Servicio de Reumatología, Hospital Nacional Edgardo Rebagliati Martins, EsSalud, Lima, Perú. \\ ${ }^{a}$ Docente invitado, Facultad de Medicina Humana, Universidad Nacional Mayor de San Marcos, Lima, Perú. \\ ${ }^{b}$ Docente, Facultad de Medicina Humana, UNMSM, Lima, Perú.
}

\begin{abstract}
Resumen
Se describe las características clínicas y de laboratorio de dos pacientes que recibieron rituximab por miopatía inflamatoria idiopática (MII). Ellas eran refractarias a tratamiento convencional con DARMES, por lo que recibieron rituximab 1 gramo cada 14 dias, en dos infusiones en ciclo semestral. En las historias clínicas se obtuvo los datos clínicos de fuerza muscular proximal, lesiones cutáneas patognomónicas, elevación de CPK, TGO, DHL y VSG, resultados de electromiografia, biopsia muscular y de piel. Ninguno de los dos casos presentó reacción medicamentosa ni infecciones durante y posterior a las infusiones. Rituximab mostró efectividad en la respuesta clínica y enzimática en estas pacientes con dermatomiositis refractarias a corticoides y DARMES tradicionales.
\end{abstract}

Palabras clave: Dermatomiositis, miopatía inflamatoria idiopática refractaria, rituximab.

Abstract

Clinical and laboratory characteristics of two patients who received rituximab for refractory idiopathic inflammatory myopathy (IIM) are described. Patients were refractory to conventional treatment with disease-modifying antirheumatic drugs (DMARDs) so they received rituximab $1 \mathrm{~g}$ dose every 14 days in two biannual cycle infusions. Data of proximal muscle strength, pathognomonic skin lesions, CPK, SGOT, LDH and ESR, results of electromyography, muscle and skin biopsy were obtained from the medical records. None of the cases presented drug reaction or infections during and following infusions. Rituximab showed effectiveness in clinical and enzymatic response in patients with dermatomyositis refractory to corticosteroids and traditional DMARDs.

Keywords: Dermatomyositis, refractory idiopathic inflammatory myopathy, rituximab.

An Fac med. 2013;74(4):331-4

\section{INTRODUCCIÓN}

Las miopatías inflamatorias idiopáticas (MII) son un grupo de entidades que tienen un trasfondo autoinmune y de etiología desconocida, cuyo cuadro clínico está dado por la debilidad muscular, a predominio proximal y simétrico; algunas de ellas presentan compromiso cutáneo. Para el diagnóstico se requiere cumplir los criterios de clasificación de Bohan y Peter, los cuales incluyen elevación de los valores de algunas enzimas musculares, presencia de un patrón miopático en la electromiografía, así como la evidencia de disminución de la fuerza muscular proximal, existiendo en algunas ocasiones lesiones dérmicas patognomónicas y la presencia de un infiltrado de células mononucleares en la biopsia muscular de las zonas comprometidas ${ }^{(1)}$. El tratamiento convencional está dado por el uso de corticoides, prednisona $1 \mathrm{mg} / \mathrm{kg} / \mathrm{día}$, durante un periodo de 4 a 6 semanas, asociada a metotrexato o azatioprina, utilizando como alternativa terapéutica a ellos la ciclosporina, tacrolimus, ciclofosfamida, micofenolato y la inmunoglobulina EV (2). Dos tercios de ellos van a presentar respuesta parcial, teniendo una tasa de letalidad entre 23 y $73 \%$ a los cinco años ${ }^{(3)}$.

En la actualidad se viene utilizando nuevas terapias, más selectivas, denominadas en su conjunto como terapia biológica. Son diversas entidades en las que se viene indicando y los resultados son alentadores, como es el caso de la artritis reumatoide y lupus eritematoso sistémico. Se las ha utilizado en base al conocimiento del trasfondo autoinmune de estas y otras entidades, como viene a ser el caso de las MII. Los trabajos publicados en el mundo, incluso en el Perú ${ }^{(4)}$, sobre terapia biológica en MII es predominantemente con rituximab y los resultados encontrados han sido exitosos. Rituximab es un anticuerpo quimérico monoclonal anti CD20, el cual está dirigido contra el antígeno que se encuentra sobre la superficie celular de la línea de linfocitos B. La depleción de estos traerá diversas alteraciones en la producción de anticuerpos, 
liberación de citoquinas y modificación en el número de células presentadoras de antígenos al linfocito T. En las biopsias de músculo de los pacientes con dermatomiositis se ha encontrado infiltrado de complejos inmunes en los vasos sanguíneos, por lo que se entiende que es un proceso mediado por la inmunidad humoral con activación del complemento. Además, en 30 a 50\% de pacientes con miopatía inflamatoria se puede encontrar la presencia de anticuerpos específicos para miopatía idiopática inflamatoria, siendo el anti Jo1 el hallado en $20 \%$, aproximadamente. Por lo descrito, se puede inferir el rol fundamental del linfocito B en la fisiopatología de las MII ${ }^{(5-7)}$.

La razón del presente trabajo es describir los hallazgos obtenidos en dos pacientes con diagnóstico de MII y que recibieron rituximab luego de habérseles catalogado como refractarios al tratamiento convencional. Creemos que el aporte de esta comunicación acrecentará el número de experiencias en el mundo respecto a los beneficios del rituximab en la MII.

\section{CASO 1}

Mujer de 33 años con antecedente de dermatomiositis que fue diagnosticada en 1999, presentando disminución de fuerza muscular proximal, $3 / 5$ en miembros superiores y $2 / 5$ en miembros inferiores, con limitación para mantener la cabeza erguida, electromiografía con evidencia de patrón miopático, lesiones cutáneas tipo Gottron y heliotropo, además de eritema en región frontal y facial, signo del chal y eritema en cuello en V. Elevación de transaminasa glutámica oxalacética (TGO) en $423 \mathrm{U} / \mathrm{L}$ (VN: 0-34 U/L), no elevación de creatinfosfoquinasa (CPK), anticuerpos antinucleares (ANA) negativo, proteína $C$ reactiva (PCR) 3,2; así mismo, elevación de temperatura, oligoartritis leve y astenia, por lo que recibió prednisona $1 \mathrm{mg} / \mathrm{kg} / \mathrm{d}$ ía en un promedio de 4 semanas, con descenso progresivo y asociado a metotrexato $12,5 \mathrm{mg} / \mathrm{sem}$, obteniendo mejoría considerable en fuerza muscular proximal $4 / 5$, en las cuatro extremidades, normalización de TGO y negativización de PCR, así como a nivel de las lesiones cutáneas. Dicho esquema de tratamiento lo recibió durante dos años, luego de lo cual abandonó hasta septiembre de 2008, cuando nuevamente presentó debilidad muscular proximal $3 / 5$ en las cuatro extremidades, imposibilidad de incorporarse de la cama, dificultad para levantarse de la silla, disfagia y presencia de lesiones cutáneas de más intensidad que en el primer episodio. Sin elevación de las enzimas musculares, PCR aumentó a 0,8 mg/dL, anti Jo1 negativo, ANA negativo. Se inició tratamiento con pulsos de metilprednisolona de $750 \mathrm{mg} /$ día por tres días consecutivos, continuando con prednisona $1 \mathrm{mg} / \mathrm{kg} / \mathrm{día}$, acompañada de metotrexato $20 \mathrm{mg}$ sc semanal. Se obtuvo mejoría parcial en fuerza muscular proximal, 4/5, pudiendo incorporarse de la silla, ausencia de disfagia; pero, el cuadro dérmico persistió con eritema facial y en dorso de las manos, signo de heliotropo, signo en chal, eritema en $\mathrm{V}$, eritema en rodillas y codos asociado a dolor difuso notable. En abril de 2009 se decidió iniciar tratamiento con rituximab $1 \mathrm{~g}$ cada 2 semanas por dos dosis, premedicación con paracetamol $1 \mathrm{~g}$, dexametasona $8 \mathrm{mg}$ y clorfeniramina 4 mg por vía EV previa a cada infusión, en la unidad de infusión de nuestro servicio, Unidad Ambulatoria de Reumatología (UNAR). No se presentó reacción adversa durante la infusión ni en el transcurso de los días. Las lesiones cutáneas comenzaron a cambiar de color a las 4 semanas aproximadamente, acompañado de desaparición del dolor generalizado. Aproximadamente a las 12 semanas no se evidenciaba lesiones activas, paciente deambulaba sin limitación alguna y continuaba con tratamiento concomitante con metotrexato $20 \mathrm{mg}$ sc semanal y prednisona $10 \mathrm{mg} /$ día. Aproximadamente a los 8 meses, pese a continuar con tratamiento, nuevamente se exacerbaron las lesiones, acompañado de disminución de fuerza muscular 4/5, sin elevación de enzimas musculares, por lo que fue necesario brindarle un nuevo ciclo de rituximab de $1 \mathrm{~g}$ cada 14 días por dos dosis, con elevación de prednisona a $20 \mathrm{mg} /$ día, luego de lo cual paciente mejoró a nivel cutáneo y en la fuerza muscular a 5/5. Además, se realizó el recuento de linfocitos CD20+ por citometria de flujo, no evidenciándose su presencia. Desde entonces, en junta médica del servicio se decidió brindar rituximab en forma continua cada 6 meses, con lo cual la paciente ha evolucionado favorablemente, no presentando exacerbación. Ha recibido en total seis ciclos de dos infusiones de rituximab cada una, hasta la actualidad, no reportándose evento adverso severo.

\section{CASO 2}

Mujer de 38 años con tiempo de enfermedad de dos años y medio, caracterizado por aparición de lesiones eritematosas puntiformes en extremidades, extendiéndose a región facial y tronco. Es evaluada por dermatólogo en mayo de 2010, quien diagnostica psoriasis y brinda tratamiento con metotrexato $15 \mathrm{mg} / \mathrm{sem}$ y lociones, con respuesta parcial. En enero de 2011 presenta exacerbación de lesiones anteriores, con aparición de nuevas lesiones tipo heliotropo y Gottron, eritema en chal, eritema facial y en $V$, acompañado de alopecia, disminución de fuerza muscular proximal 2/5 en extremidades, con incapacidad para deambular y mantenerse sentada, artralgias, ANA positivo 1/1280 patrón nuclear moteado, PCR $1,2 \mathrm{mg} / \mathrm{dL}$, CPK $10730 \mathrm{U} / \mathrm{L}$, TGO 183 U/L, dehidrogenasa láctica (DHL) $2630 \mathrm{U} / \mathrm{L}$, por lo que recibió prednisona $1 \mathrm{mg} / \mathrm{kg} / \mathrm{d}$ ía asociado a metotrexato $10 \mathrm{mg}$, ascendiendo hasta $20 \mathrm{mg} / \mathrm{sem}$. Tuvo disminución de CPK hasta 3 131, luego de lo cual no continuó el descenso. La fuerza muscular proximal mejoró hasta $-3 / 5$, pero el cutáneo persistió. La paciente podía deambular con apoyo. Se mantuvo dicho tratamiento por 9 meses. En noviembre de 2011 acudió a consulta en silla de ruedas; presentaba fuerza muscular proximal en $2 / 5$ en miembros superiores y $3 / 5$ en miembros 


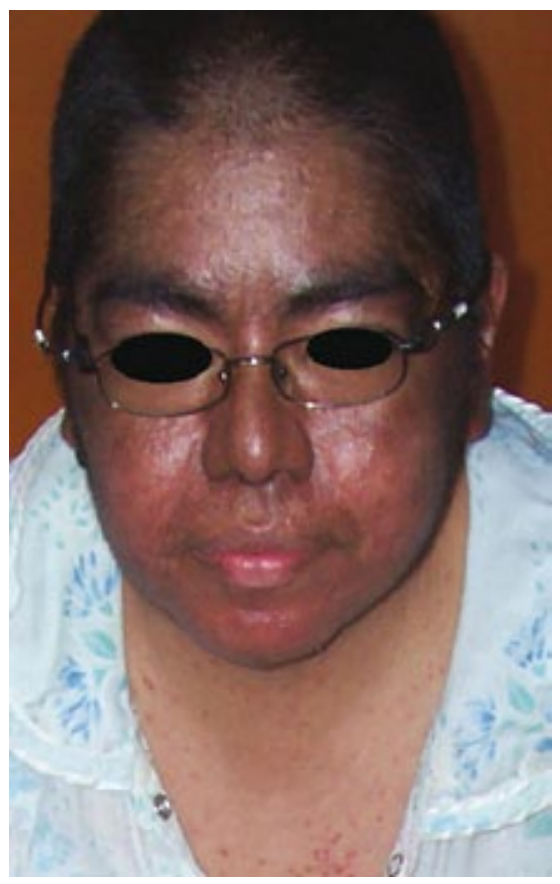

Figura 1. Caso 2. Previo al tratamiento con rituximab, obsérvese lesiones eritematosas en facies y región pectoral, alopecia notable y lesiones tipo heliotropo en ambos párpados.

inferiores; no podía levantarse de la cama ni incorporarse del sillón. Las lesiones cutáneas se exacerbaron (figura 1), CPK 3743 U/L, TGO 158 U/L. Se decidió incrementar la dosis de prednisona a $1 \mathrm{mg} / \mathrm{kg} / \mathrm{dí}$. Se intentó iniciar ciclosporina, pero presentó intolerancia, por lo que se decidió subir la dosis de metotrexato a $22,5 \mathrm{mg}$ sc semanal e iniciar rituximab $1 \mathrm{~g}$ cada 14 días por dos ocasiones, con premedicación en la UNAR consistente en paracetamol $1 \mathrm{~g}$, dexametasona $8 \mathrm{mg}$ ev y clorfeniramina $4 \mathrm{mg}$ ev, el 5 y 20 de diciembre de 2011. No presentó eventos adversos durante ni después de la administración del tratamiento. Aproximadamente a las 2 semanas de la primera infusión, la paciente refirió sentir mejoría de la fuerza muscular $3 / 5$, pudiéndose levantar de la silla con impulso; las lesiones eritematosas comenzaron a cambiar de color; el malestar general disminuyó. A las 16 semanas se normalizaron los niveles de CPK 189 U/L, TGO 22U/L, Hb 13 g/ dL y PCR negativo; podía deambular sin apoyo, acudiendo a la cita de con- sultorio externo sin compañía; las lesiones mejoraron considerablemente (figura 2). Hasta el momento no se ha comunicado evento adverso serio.

\section{DISCUSIÓN}

Existen diversos trabajos publicados en la actualidad -comunicación, serie de casos y un ensayo clínico piloto-, en los que se describe los beneficios obtenidos con rituximab, todos ellos en pacientes con MII refractarios al tratamiento convencional ${ }^{(8-18)}$ y existiendo un solo artículo donde fue indicado como de primera línea ${ }^{(19)}$. Las evaluaciones de respuesta han sido referidas al compromiso cutáneo, niveles de enzimas musculares, fuerza muscular proximal medida por medio de la ponderación del clínico o a través de algún instrumento de medición, recuento de linfocitos CD20+; así mismo, se ha venido considerando el tiempo en el que fue necesario brindar nuevamente el fármaco, basado en la reactivación de la enfermedad.

Nuestros pacientes mostraron mejoría considerable en los aspectos clínicos y de laboratorio, hallazgos que son acordes con los trabajos previos, incluidos los de origen latinoamericano ${ }^{(4,20)}$. Es de destacar que en los trabajos que incluyeron un mayor número de pacientes ${ }^{(8,10)}$, se encontró variaciones significativamente favorables en lo que respecta a los valores del CPK, no ocurriendo lo mismo con la fuerza muscular. En ambos trabajos no se describió la evolución de las lesiones cutáneas de los pacientes con dermatomiositis. Un estudio abierto en el que se evaluó a ocho pacientes con dermatomiositis ${ }^{(12)}$, no mostró mejora considerable en el ámbito del compromiso dérmico, contrario a otro estudio abierto en el que se describe como uno de los hallazgos principales a destacar ${ }^{(14)}$. La explicación a esta diferencia estaría dada, quizá, por la diferencia en la composición genérica de ambos estudios, la diferencia de los esquemas de tratamiento con rituximab utilizados, la consideración del nivel basal de la fuerza muscular.



Figura 2. Caso 2. Paciente 6 meses post infusión de rituximab. No se evidencia alopecia;

las lesiones tipo heliotropo han cedido completamente, eritema facial y pectoral casi ausente.

En nuestro trabajo utilizamos el esquema de tratamiento similar al que se aplica a los pacientes con artritis reumatoide, un gramo de rituximab cada 14 días en dos ocasiones. En los trabajos iniciales se empleó esquemas similares aplicados a los pacientes con linfoma no Hodgkin, como es $375 \mathrm{mg} / \mathrm{m}^{2}$ semanalmente por 4 dosis. La descripción de efectividad en el tratamiento en los diversos trabajos, según ambos esquemas, es similar, a excepción de un estudio abierto que utilizó el esquema de $1 \mathrm{~g}$ bisemanal por dos ocasiones, donde los resultados fueron modestos ${ }^{(12)}$.

Una de nuestras pacientes mostró mejoría desde el punto de vista de las lesiones cutáneas y un incremento en la fuerza muscular a las dos semanas de la primera infusión, dato importante, no descrito en otros reportes, pues en dos de los trabajos se menciona que esto comenzó a las 5 semanas en promedio, casi similar a nuestro primer caso descrito. Se obtuvo una respuesta completa, desde el punto de vista de laboratorio 
(CPK), a las 16 semanas, aproximadamente, donde se normalizó dicho parámetro. Así mismo, las lesiones remitieron por completo en una de ellas y en la segunda se obtuvo una respuesta casi exitosa, como se evidenció en la fotografía. En este aspecto, los trabajos publicados muestran resultados no tan uniformes, donde algunos obtienen respuesta a las 4 semanas, siendo esta respuesta máxima a las 12 semanas ${ }^{(4,10,14)}$, mientras que en otros estudios esta es alcanzada a los 5 meses ${ }^{(9)}$.

En lo referente a la seguridad de rituximab, en nuestra experiencia no se presentó evento adverso serio, al igual que la gran mayoría de trabajos.

Podemos concluir, luego de describir nuestros hallazgos y al contrastarlos con otras experiencias a nivel mundial, que rituximab puede ser considerada en el arsenal terapéutico para los casos de MII refractarios al tratamiento, especialmente en dermatomiositis. Es necesaria la realización de ensayos clínicos para evaluar la dosis y el régimen de administración más adecuado, así mismo para evaluar parámetros de seguridad en el tiempo.

\section{REFERENCIAS BIBLIOGRÁFICAS}

1. Dalakas MC, Hohlfeld R. Polymyositis and dermatomyositis. Lancet. 2003;362(9388):971-82.
2. Ytterberg SR. Treatment of refractory polymyositis and dermatomyositis. Curr Rheumatol Rep. 2006;8:167-73.

3. Airio A, Kautiainen $\mathrm{H}$, Hakala M. Prognosis and mortality of polymyositis and dermatomyositis patients. Clin Rheumatol. 2006;25:234-9.

4. Mendoza-de los Santos O, Berrocal A, Calvo A. Rituximab en el manejo de miositis refractaria: a propósito de dos casos. Rev Soc Peru Med Interna. 2010;23(3):109-11.

5. Love LA, Leff RL, Fraser DD, Targoff IN, Dalakas M, Plotz PH, Miller FW. A new approach to the classification of idiopathic inflammatory myopathy: myositis-specific autoantibodies define useful homogeneous patient groups. Medicine (Baltimore). 1991;70(6):360-74.

6. Engel AG, Arahata K. Mononuclear cells in myopathies: quantitation of functionally distinct subsets, recognition of antigen specific cell-mediated cytotoxicity in some diseases, and implications for the pathogenesis of the different inflammatory myopathies. Hum Pathol. 1986;17:704-21.

7. Miller FW. Myositis-specific autoantibodies. Touchstones for understanding the inflammatory myopathies. J Am Med Assoc. 1993;270:1846-9.

8. Mahler EAM, Blom M, Voermans NC. Rituximab treatment in patients with refractory inflammatory myopathies. Rheumatology. 2011;50:2206-13.

9. Sánchez-Fernández S, Carrasco JA. Rojas LM. Eficacia de rituximab en dermatomiositis y polimiositis refractarias al tratamiento convencional. Reumatol Clin. 2013;9(2):117-9.

10. Couderc M, Gottenberg JE, Mariette X, Hachulla E, Sibilia J, Fain O, et al. Efficacy and safety of rituximab in the treatment of refractory inflammatory myopathies in adults: results from the AIR registry. Rheumatology. 2011;50:2283-9.

11. Garcia FJ, Chinchilla E, Castillo MJ, González C, Ocaña C, Sánchez J. Evaluación de la eficacia del tratamiento con rituximab asociado a ciclofosfamida en pacientes con miopatía inflamatoria idiopática refractaria. Med Clin (Barc). 2010;135:256-9.

12. Chung L, Genovese MC, Fiorentino DF. A pilot trial of rituximab in the treatment of patients with dermatomyositis. Arch Dermatol. 2007;143:763-7.
13. Mok CC, Ho LY, To CH. Rituximab for refractory polymyositis: an open-label prospective study. J Rheumatol. 2007;34:1864-8.

14. Levine TD. Rituximab in the treatment of dermatomyositis: an open-label pilot study. Arthritis Rheum. 2005;52:601-7.

15. Noss EH, Hausner-Sypek DL, Weinblatt ME. Rituximab as therapy for refractory polymyositis and dermatomyositis. J Rheumatol. 2006;33:1021-6.

16. Sultan SM, Ng KP, Edwards JC, Isenberg DA Cambridge G. Clinical outcome following B cell depletion therapy in eight patients with refractory idiopathic inflammatory myopathy. Clin Exp Rheumatol. 2008;26:887-93.

17. Chiappetta N, Steier J, Gruber B. Rituximab in the treatment of refractory dermatomyositis. J Clin Rheumatol. 2005;11:264-6.

18. Lambotte O, Kotb R, Maigne G, Blanc FX, Goujard C, Delfraissy JF. Efficacy of rituximab in refractory polymyositis. J Rheumatol. 2005;32:1369-70.

19. Haroon M, Devlin. Rituximab as a first-line agent for the treatment of dermatomyositis. J Rheumatology Int. 2012;32(6):1783-4.

20. Yáñez VJ, Cisternas MM, Saldias HV, Saldias PF. Refractory dermatomyositis associated with chronic organizing pneumonia treated with rituximab: report of one case. Rev Med Chil. 2009;137(1):88-93.

Artículo recibido el 22 de febrero de 2013 y aceptado para publicación el 14 de marzo de 2013.

\section{Conflicto de intereses:}

Los autores niegan la existencia de conflicto de intereses.

\section{Correspondencia:}

Servicio de Reumatología, Hospital Nacional Edgardo Rebagliati Martins, EsSalud

Av. Edgardo Rebagliati No490, Jesús Maria, Lima

11, Perú

Teléfono: 51-01-2654901, anexo 3438

Correo electrónico: egasal2003@yahoo.es. 